\title{
Microbiological evaluation of women with vulvovaginitis and cervicitis
}

\author{
Moro, Dauphin Dighitoghi and Ali, Chizoba Geraldine.
}

${ }^{1}$ Department of Microbiology, Faculty of Science, Lagos State University, Nigeria

\section{Correspondence}

Dr Dauphin Dighitoghi Moro, Department of Microbiology,Faculty of Science, Lagos State University, Nigeria.

Email:drddmoro@gmail.com

\section{Funding information}

Grant sponsor and grant number: self funding

\begin{abstract}
:
Introduction: The vaginal ecosystem is a complex environment that consists of interrelationships among endogenous microflora, their metabolic products, the host's metabolic products, oestrogen and the $\mathrm{pH}$ level. The endocervix however is a sterile environment, which remains susceptible to many infections.

Aims: An investigation of cervico-vaginal infections amongst female patients aged 14-63 years attending two private hospitals in Lagos, Nigeria was carried out.

Materials and Methods: A total of 480 female patients constituting 444 with and 36 without vaginal discharge were examined. Both high vaginal (HVS) and endocervical swab (ECS) were taken from these patients and subjected to microbiological examinations. Antibiotics susceptibility pattern was determined using the disc diffusion technique.

Results: Eight different 8 species of microorganisms were isolated. The most predominant was Gardnerella vaginalis, which accounted for 264 $(49 \%)$ of the total isolates, followed by Candida albicans, $120(22 \%)$, Escherichia coli, 76(14\%) Trichomonas vaginals, 28(5\%) and Neisseria gonorrhoeae,32(6\%). Other were Proteus mirabilis, $8(1.5 \%)$ and Streptococcus pyogenes $4(0.7 \%)$. Mixed infections were observed in $20 \%$ of the patients studied.

Conclusion: The health implication of the organisms isolated especially the high incidence of Gardnerella vaginosis in women of reproductive age can predispose them to sexually transmitted diseases (STDs), spontaneous abortion, pre-term delivery among others. The bacterial isolates were most sensitive to Gentamycin, Pefloxacine and Ceftriaxone, while most of them were resistant to Ampicillin and Tetracycline which are commonly available and abused over-the-counter drugs.

Keywords: Vulvovaginitis, cervicitis, monogamy, microbial pathogens, endogenous microflora.
\end{abstract}




\section{INTRODUCTION}

The vaginal ecosystem is a complex environment that consists of interrelationships among endogenous microflora, metabolic products of the microflora and host, estrogen and the $\mathrm{pH}$ level. The dynamic equilibrium of the ecosystem is often challenged by both endogenous and exogenous factors [1]. The endocervix is lined with columnar epithelium which is constantly being replaced with new cells generated by the division of the basal cells. It is a sterile environment, which remains susceptible to many infections [2]. Vaginitis and cervicitis are reproductive tract infections (RTIs) which are frequent and troublesome disorders during reproductive life of women and constitutes great socio-economic and medical problems [3]. Both infections are trivialized by the medical profession, vaginal and cervical discharge in adult women are not only extremely common but cause considerable distress often characterized by marked suffering [4]. Vaginitis is more common than cervicitis and it is the most common gynaecological problem encountered by physicians providing primary care for women [1]. Vaginitis occurs due to alteration of the vaginal ecosystem's microflora by yeast, Gram positive and Gram negative aerobes which are facultative and obligate anaerobic bacteria [5]. The predominant bacterial group is the lactobacilli. An altered vaginal ecosystem usually results from combination of factors, such as use of medications, repeated douching or self diagnosis or self treatment [6]). Other of such factors include antibiotics, hormones, contraceptives, vaginal medications, sexual intercourse, sexually transmitted diseases (STDs), stress etc. [6]. The normal $\mathrm{pH}$ level of the vagina which is between $3.5-4.2$ is vital to stabilize the vaginal ecosystem. Lactobacilli suppress the growth of the Gram negative and Gram positive facultative and obligate anaerobes and maintain normal $\mathrm{pH}$ through the production of lactic acid [1]. When the $\mathrm{pH}$ level rises, the growth of lactobacilli is inhibited while the growth of pathogens is facilitated, hydrogen ion concentration is lowered as well, so adherence of pathogens to the vaginal epithelial cells is favoured. Several bacteria and other microbes have been implicated in vulvovaginitis and cervicitis [7]. This study was designed to evaluate the incidence of bacterial pathogens, identify and characterize bacterial pathogens associated with vaginitis and cervicitis as well as determine the antibiotic susceptibility patterns of bacteria from adult women.

\subsection{STUDY AREA AND SUBJECTS.}

This study was carried out in ljora-Badia, Lagos. All the patients who were interviewed before specimens were collected having obtained informed consent with their ages ranging from 14-63 years. A total of 480 females were selected for the study, of which 444 were symptomatic and 36 were without vaginal discharge. A copy of questionnaire specially designed for this study was filled by each patient.

\subsection{SAMPLE COLLECTION AND ANALYSIS}

With the patient on the examination bed, careful examination of external vaginal surfaces was done to determine the presence of genital warts, lesions of herpes genitalis and labial oedema, A sterilized cuscos speculum was then gently inserted into the vagina by a gynaecologist and obstetrician. The vaginal walls were examined and two swabs of high vaginal swab (HVS) and two- endocervical swab (ECS) were taken from each patient. After the withdrawal of the speculum, the $\mathrm{pH}$ of the discharge was determined by inserting a strip of the indicator paper in the discharge collected in the lower speculum [8].

\subsection{MICROBIOLOGICAL ANALYSIS.}

\subsubsection{BACTERIOLOGICAL STUDIES}

The swab specimens were divided into two sets. The first set were cultured on well-dried media which included MacConkey agar, Chocolate agar, blood agar, Sabouraud dextrose agar and Thayer -Martin agar. The blood agar, MacConkey agar and Sabouraud dextrose agar were incubated aerobically while chocolate agar and Thayer- Martin agar were incubated at $370 \mathrm{C}$ in candle extinction jars for $24 \mathrm{~h}$ to $48 \mathrm{~h}$ [8].Identification of all bacterial isolates was carried out on the basis of cultural, morphological and biochemical characteristics according to Cheesbrough, [8].

\subsubsection{WHIFF OR AMINE TEST}

A swab of the vaginal discharge was agitated in a tube containing about $1 \mathrm{ml}$ of normal saline $(0.85 \%)$.One drop of the resulting suspension was put on a microscopic slide and a drop of $10 \% \mathrm{KOH}$ was added. A fishy odour due to liberation of amines indicated a positive result while absence of a fishy odour was regarded as negative. When the suspension was covered with a cover slip and used for wet mount preparation,, observed with $\times 10$ and $\times 40$ objectives, hyphal forms of yeast cells, clue cells appeared as normal epithelial cells covered with tiny coccobacilli, while yeast cells appear as oval budding cells [8].

\subsubsection{WET MOUNT PREPARATION AND ANALYSIS}

About $1 \mathrm{ml}$ of normal saline was added to the swab of HVS. A drop of the resulting suspension was placed on a microscopic slide, covered with a cover slip and examined under x10 and x40 objectives. Clue cells appeared as normal epithelial cells covered with tiny coccobacilli, budding yeast cells, motile bacteria, Trichomonads as motile flagellated organisms and polymorphonuclear cells (pus cells) [8].

\subsubsection{ANTIBIOTICS SUSCEPTIBILITY TEST}

The standard disc diffusion method and zone-size interpretation chart of Kirby-Bauer using McFarland's standard was employed \{8). The following 
concentrations of the antibiotics were used: gentamycin (10mcg), chloramphenicol $(10 \mathrm{mcg})$, nalidixic acid $(30 \mathrm{mcg})$, nitrofurantoin $(10 \mathrm{mcg})$, cotrimoxazole $(25 \mathrm{mcg})$, tetracycline $(30 \mathrm{mcg})$, ampicillin $(25 \mathrm{mcg})$, peflacin $(10 \mathrm{mcg})$ and ceftriaxone $(25 \mathrm{mcg})$. Escherichia coli (NCTC 10418) was used as used as a control.

\subsection{RESULTS AND DISCUSSION}

\subsection{RESULTS}

Out of 480 patients examined, four hundred and forty four $((93 \%)$ had vaginal and endocervical infections while the remaining $36(7 \%)$ had no infections.s Table 1 shows the age distribution of women examined. $88.3 \%$ of the subjects were 40 years and below. Vulvovaginitis and cervicitis reduced with age.

Table 1: Age distribution ot women examined.

\begin{tabular}{|l|l|l|}
\hline Age & No of patients & Percentage \\
\hline $10-20$ & 32 & 6.67 \\
\hline $21-30$ & 204 & 42.50 \\
\hline $31-40$ & 188 & 39.17 \\
\hline $41-50$ & 36 & 7.50 \\
\hline $51-60$ & 16 & 3.33 \\
\hline $61-70$ & 4 & 0.83 \\
\hline Total & 480 & $100 \%$ \\
\hline
\end{tabular}

More than half of the women practiced monogamy and one quarter practiced polygamy (Table 2)

\section{Table L: Marita status of women studied}

\begin{tabular}{|l|l|l|}
\hline Marital status & Noof patients & Percentage \\
\hline Single & 108 & 22.50 \\
\hline Monogamy & 252 & 52.50 \\
\hline Polygamy & 120 & 25,00 \\
\hline Total & 480 & $100 \%$ \\
\hline
\end{tabular}

About half of the subjects did not practice any form of contraceptive while condom and coil were the usually practiced contraceptive methods (Table3).

Table 3: Distribution of women on contraceptive use

\begin{tabular}{|l|l|l|}
\hline Type of contraceptive & No of patients (HVS and EVS) & Percentage \\
\hline Condom & 108 & 22.5 \\
\hline Coil & 96 & 20.0 \\
\hline Injectables & 36 & 7.5 \\
\hline UUD & 4 & 0.83 \\
\hline NIL & 236 & 49.20 \\
\hline Total & 480 & $100 \%$ \\
\hline
\end{tabular}

Table 4 shows that G. vaginalis, C. albicans, and E.coli were the most implicated isolates in vaginitis and cervicitis.

Table 4: Organisims isolated and sites of isolation

\begin{tabular}{|l|l|l|l|l|}
\hline Organisms & Isolates from HVS & Isolates from ECS & Total Isolates & Percentage \\
\hline Gardnerall raginalis & 240 & 24 & 264 & 49 \\
\hline Candida albicans & 96 & 24 & 120 & 22.1 \\
\hline Escherichina coli & 48 & 28 & 76 & 14.0 \\
\hline Triclomononas raginalis & 8 & 20 & 28 & 5.0 \\
\hline Neisseria gonorinhoene & 4 & 28 & 32 & 6.3 \\
\hline Colform & 8 & - & 8 & 1.5 \\
\hline Protelus mirabilis & 4 & 4 & 8 & 1.5 \\
\hline Streptococcus pyogenes & 4 & - & 4 & 0.7 \\
\hline Total & 412 & 128 & 540 & 100 \\
\hline
\end{tabular}

Single and mixed infections were found. Single infections constituted $71.6 \%$ and only $17.6 \%$ were mixed (Table 5).

Table 5: Distribution of microbes in the samples analyzed

\begin{tabular}{|c|c|c|}
\hline Organism & No recovered & Percentage \\
\hline Gardnerella voginalis & 208 & 43.3 \\
\hline Candido albicans & 72 & 15 \\
\hline Escherichia coli & 40 & 8.3 \\
\hline Trichomonas vaginalis & 4 & 0.8 \\
\hline Neisseria gonorrhoeace & 24 & 5 \\
\hline Proteus mirabilis & 4 & 0.8 \\
\hline Candido albicans+Gardnerella vaginalis & 32 & 6.7 \\
\hline Gardnerellat Trichomonos & 24 & 5 \\
\hline \begin{tabular}{|l} 
CandidotE.coli \\
\end{tabular} & 16 & 3.4 \\
\hline Ecolit colliform & 8 & 1.7 \\
\hline EcolitProteustStreptococcus pyogenes & 4 & 0.8 \\
\hline \begin{tabular}{|l|} 
NIL infections \\
\end{tabular} & 36 & 7.5 \\
\hline Total & 480 & $100 \%$ \\
\hline
\end{tabular}

Getamicin, nitrofurantoin, perfloxacin and ceftriaxone showed high in-vitro efficacy against most isolates tested while the commonly used antibiotics were resisted by the isolates (Table 6).

Table 6: Antibiotics susceptibility pattern (\%) of bacterial isolates

\begin{tabular}{|c|c|c|c|c|c|c|c|c|c|}
\hline Organism & Gen & Chl & $\mathrm{Nal}$ & Nitt & $\operatorname{Cot}$ & Tet & Amp & Pef & Cef \\
\hline E. coli $(76)$ & 89 & 26 & 84 & 89 & 32 & 0 & 0 & 100 & 95 \\
\hline Neisseria gonorrhoeve (32) & 75 & 75 & 38 & 50 & 50 & 25 & 12 & 100 & 100 \\
\hline Proteus mirrobilis (4) & 100 & 0 & 50 & 100 & 0 & 0 & 0 & 100 & 100 \\
\hline Colliforn (8) & 100 & 0 & 50 & 100 & 100 & 0 & 0 & 100 & 100 \\
\hline Streptococcus pyogenes (4) & 100 & 0 & 0 & 100 & 0 & 0 & 0 & 100 & 100 \\
\hline
\end{tabular}


KEY:

Gen: Gentamicin

Chl: Chrloramphemicol

Nal: Nalidixic acid

Nit: Nitrofurantoin

Cot: Cotrimoxazole

Tet: Tetracyline

Amp: Ampicillin

Pef: Perfloxacin

Cef: Ceftriaxone

\subsection{DISCUSSION}

The study shows that majority of the women with both infections were between 10-40 years, thereby constituting $88.3 \%$ of the subjects. This age range constitutes the most sexually active age group, thus suggests the likelihood of sexual intercourse as a predisposing factor to vulvovaginitis and cervicitis [1]. Women who practice monogamy had a higher incidence of both infections. Such women are likely to have more frequent sexual intercourse which may be responsible for the high incidence of vulvovaginitis and cervicitis as earlier reported by Virella, [9]. Williams et al [10] also reported that frequent sexual intercourse predisposes women to vulvovaginitis and cervicitis among women who practice monogamy. This was corroborated by the finding whereby the women used as control who cut across the various marital status showed no evidence of infection, thus showing that these infections are highly symptomatic. An interesting finding from this study is that the women who did not use any contraceptive harboured no pathogen. This shows that contraception appears to be associated with vulvovaginitis and cervicitis perhaps as their side effect. Patients who used condoms, coils and IUCDs had higher incidences of both infections Eight different species of microorganisms were isolated and identified from the vaginal and cervical discharges of patients studied. The microorganisms isolated were mostly bacteria that have been associated with vaginitis and cervicitis at one time or the other e.g.Gardnerella vaginalis, Escherichia coli, Neisseria gonorrhoeae, Proteus mirabilis and Streptococcus pyogenes. A fungus - Candida albicans and a protozoanTrichomomnas vaginalis were also isolated. Gardnerella vaginalis was the most prevalent organism in this study accounting for 49 OC of the cases. This agrees with the works of Govender et al. [11] in South Africa, whereby $52 \%$ of women studied had Gardnerella infections. Roger et al [12] also reported that Gardnerella vaginalis was found in $56 \%$ of the women studied in Michigan. According to CDC [13] and Williams et al [10], Gardnerella vaginalis accounts for $60 \%$ for vulvovaginal infections in women worldwide. The clue cells are the most sensitive and specific signs of Gardnerella vaginosis especially when seen in wet mount preparation of vaginal discharge $[4,6]$. The amine production is as a result of metabolic byproducts produced primarily by anaerobic bacteria associated with Gardnerella vaginosis [1,3]. According to Thomason et al. [5], Gardnerella vaginalis lowers LASU Journal of Research and Review in Science the vaginal tissue's redox potential and elevates vaginal $\mathrm{pH}$, these two conditions are known to be associated with increased infective potential [1]. Govender et al. [11] associated high prevalence of Gardnerella vaginalis in asymptomatic pregnant women with adverse pregnancy complications such as preterm labour, premature rupture of the membrane and chorioamnionitis. Candida albicans was found in $22 \%$ of the patients studied. Candida albicans is present in $40-80 \%$ of healthy people as part of the normal intestinal flora and $30 \%$ of women without disease symptoms have Candida albicans present in their genital tract [9]. The primary medical significance of candidial infection in candidemia whereby there is dissemination of Candida through the bloodstream, immune-compromised patients particularly those with specific defects of cell mediated immunity to Candida albicans are likely to develop disseminated skin and mucosal infections or organ infections such pneumonia, endophthalmitis and kidney infections [1 ]. The high incidence of Candida albicans may result in superficial candidiasis which involves the skin and mucosa as well as endocarditis particularly in patients receiving broad spectrum antibiotics [ 9 ]. E. coli had incidence of $14 \%$ from this study, an organism which is the commonest cause of cystitis and other urinary tract infections like pyelitis and pyelonephritis [8]. Virulent strains of E. coli cause gastroenteritis especially in infants and neonatal meningitis in addition to sepsis, wound infection, peritonitis, secondary pneumonia as well as iatrogenic and nosocomial infections [ 9 ]. Enterohaemorrhagic $\mathrm{E}$. coli is the most virulent uropathogenic strain of $E$. coli which produces haemolysins which are generally cytotoxic. None of the E. coli was however identified to the strain level in this study. Neisseria gonorrhoeae had 6\% incidence. Virella [ 9 ] reported that about 3 million cases are reported worldwide annually, with about $90 \%$ cases in women and $40 \%$ cases in men which are frequently asymptomatic. According to Cheesbrough [8], the highest incidence occurs in adults between 20 and 24 years of age and of low socioeconomic status living in urban areas. This agrees with our finding as all the 32 patients were between $20-40$ years and were living in ljoraBadia one of the remotest areas in the Lagos metropolis where sexual promiscuity is very common. Cervicitis is the predominant manifestation of gonococcal infection in women with complications which include PID, anorectal gonorrhoea and disseminated gonococcal infection (DGI) [14,15]. PID occurs in $10-20 \%$ of women with endocervical gonorrhoea, with complications such as acute salpingitis, tubo-ovarian abscess, pelvic peritonitis, ectopic pregnancy, infertility and chronic pelvic pain which are likely to be common among the subjects $[8,14]$. Trichomonas vaginalis had $5 \%$ incidence in this study. Williams et al (10) reported that $\mathrm{T}$. vaginalis occurs in $10-25 \%$ of women and an estimated 5 million new cases occur each year with $10 \%$ of occurrence in women seeking treatment for an STD. Trichomoniasis 
is a significant cause of morbidity in women and is also associated with dysuria, increased urinary frequency, vaginitis and cervicitis [15,16,17]. Women with trichomoniasis often have a significantly increased incidence of endometritis and postpartum fever. A higher prevalence of trichomoniasis was reported in women with cervical carcinoma than in normal women and $T$. vaginalis infection was suggested as a predisposing condition for development of cervical carcinoma [16, 17]. Soper and Bump [17, 18 ] reported that trichomoniasis is responsible for a significant proportion of non-gonococcal urethritis and prostatitis as well as some cases of balanoposthitis, epidydimitis, urethral stricture and rarely infertility. Gentamycin, pefloxacin, nitrofurantoin and ceftriaxone showed high in-vitro efficacy against the bacterial isolates. The high bacterial resistance showed against the most commonly used antibiotics such as tetracycline, ampicillin, cotrimoxazole and chloramphenicol may be due to abuse of such antibiotics through selfmedication, incomplete dosage among others [19,20]. This emphasizes the need to incorporate into our health care delivery system the use of antibiotics only through recommendation by physicians, after antibiotics susceptibility patterns of bacterial isolates from patients had been carried out. Conclusion: Majority of the infected women fell within the age range of 10-40 years, which is the most sexually active age group. Women who practiced monogamy, are likely to have frequent sexual intercourse which may likely account for the high incidence of both infections.Contraception appears to be associated with the vulvovaginits and cervicitis in the women studied, as those who did not use any contraceptive had no pathogen. Women who used condoms, coils and IUCDs had more infections. Single infections were more predominant as combined infections were fewer. Bacterial isolates showed high in-vitro susceptibility to gentamycin, nitrofurantoin, pefloxacin and ceftriaxone but high resistance to the commonly used antibiotics due to abuse of such drugs commonly purchased over the counter.

\section{CONCLUSION}

The health implication of the organisms isolated especially the high incidence of Gardnerella vaginosis in women of reproductive age can predispose them to sexually transmitted diseases (STDs), spontaneous abortion, pre-term delivery among others. The bacterial isolates were most sensitive to Gentamycin, Pefloxacine and Ceftriaxone, while most of them were resistant to Ampicillin and Tetracycline which are commonly available and abused over-the-counter drugs.

\section{ACKNOWLEDGEMENTS}

We thank the staff and management of hospital used particularly Dr. Amuda Olawale for his wonderful support and assistance towards the success of this study

\section{AUTHORS' CONTRIBUTIONS}

Dr Moro,D.D, conceived, initiated and funded the project, wrote the paper and processed the paper for publication.Ali Chizoba Geraldine carried out sample collection and laboratory analysis.

\section{REFERENCES}

[1] ACOG technical bulletin (1996) Vaginitis. Internet J. Gynaecol. Obstets. 54:297-302 .

[2] Jenny, C., Hooten, T. M., Bowers, A. et al. (1990) Sexually transmitted disease in victims of rape. $\mathrm{N}$. Eng. J. Med. 322: 713-716.

[3] Sobel, J.D. (1990) Vaginal infections in adult women. Med Clin. North Am. 74: 15751601.

[4] Adekunle, O.A. and Ladipo, O.A. (1996) Reproductive infections in Nigeria: Challenges for a fragile health infrastructure. In German, A., Holmes, K., Piot, P. and Wassertier, A. (Eds.) Textbook on reproductive tracts infection. Plenum Press, New York, pp. 297-316.

[5] Thomason, J.L., Sheldon, M. , Nancy, J. (1991) Bacterial vaginosis: Current review with indications for asymptomatic therapy. Am. J. Obstet. Gynecol. 1165: 1210-1217.

[6] Mardh, P.A. (1991) The vaginal ecosystem. Am. J. Obstet. Gynecol. 165: 163-168 Martens, M.G. (1993) Vulvovaginalis. In Rakel, R.E. eds Conns Current therapy. WB Saunders and Co., Philadelphia, pp. 1065-1069.

[7] Adinma, J.I.B., Okwoli, N.R., Agbai, A.O. and Unaeze, N.C. (2000) Gardnerella vaginitis: A comparison of two methods of laboratory detection. Nig. Quart. J. Hosp. Med. 10 (1): 38-40.

[8] Cheesbrough, M. (2001) Identification of Microorganisms in Medical laboratory Manual for Tropical countries Vol. II Pp. 252-280.

[9] Virella, G. (1997) Intracellular bacteria, Neisseria, Sexually transmitted diseases: In Microbiology and infectious diseases, 3rd ed. Williams \& Williams Sci.

[10] Williams, D.M., Smith, J.J., Soble, J.J. et al. (2004) Sexually transmitted disease. J. Urol. Channel: 1 -end .

[11] Govender, L., Hoosen, A.A., Moodley, J. and Moodley, P. (1996) Bacterial vaginosis and associated infections in pregnancy. Intern. J. Gynaecol. Obstet. 55: 23-28

[12] CDC \{2004\}: 2002 Laboratory guidelines Screening, tests to defect Chlamydia trachomatis and Neissaria gonorrhoeae infections pg. 1-13. 
[13] Center for Disease Control and prevention (CDC) (2004) 2000 laboratory guidelines screening tests to detect Chlamydia trachomatis and Neisseria gonorrhoeae. Atlanta Georgia pp 1-13.

[14] Okonoua, F.E, Ako-Nai, K.A and Moro, D.D. \{1995\} Lower genital infections in infertile Nigerian woman compared with control Genitourin. Med. 71: 163-168. UK.

[15] Ajayi, G.O. and Omilabu, S. (2000) Chlamydia in fertile and infertile Nigerian women: A Serologic and hysterosalpingraphic study. Nig. Venel. Diseas. Assoc. 1:38-42 .

[16] Rein, M.F., Sullivan, J.A. and Mandela G.L. (1986) Trichomonocidal activity of human polymorphonuclear neutrophils: Killing by disruption and fragmentation. $J$ Infect. Dis. 142: 575 - 580 [17] Soper, D.E. and Bump, R.C. (1990) Bacterial vaginosis and trichomonas vaginitis are risk factors for Cuff cellulitis after abdominal hysterectomy. Am. J. Obstet. Gynecol. 163:1016-23.

[18] Wei, S.O.N. and Daqing City, T.C.M.(2015). To explore the clinical effect of treatment of chronic cervicitis and vaginitis. China Health Standard Manag. 16: 10-15.

[19] Polk, J., Mattson, S. and Nyirjesy, R. (2015) Chronic cervicitis presenting features and responses to therapy. Am. J. Obstet. Gynecol. 6: 907-912 .

[20] Dovletkhanova, E.R. (2012) Complex treatment of chronic cervicitis. Obstet. Gynecol. 4: 83-86. 